\title{
Pesquisa, intervenção e tecnologias: \\ DISPOSITIVOS DE VIRTUALIZAÇÃO DE COLETIVOS
}

\author{
Grace Vali Freitag Tanikado Cleci Maraschin ${ }^{\star}$
}

\begin{abstract}
RESUMO
Este trabalho tem como objetivo discutir uma pesquisa que consistiu em uma intervenção, com a utilização de ferramentas tecnológicas, no campo da psicologia social. Tomamos como intercessores teóricos proposições de Gilbert Simondon, René Lourau e Pierre Lévy. Tal composição de perspectivas ganha corpo na prática de uma oficina tecnológica em um serviço da rede pública de atenção à saúde mental, na qual os trabalhadores construíram seu website. As tecnologias operaram como dispositivos de virtualização das práticas do serviço, provocando sua problematização e produzindo analisadores. Um desses analisadores foi a coabitação de discursos dicotômicos sobre cuidado em saúde mental, derivados do modelo manicomial e do proposto pela reforma psiquiátrica. A oficina conformou-se como espaço de conversa/produção entre os trabalhadores e pesquisadores, proporcionada pela relação mediada pela realização do website. Apontamos, assim, que a operatividade técnica possibilitou condições para a emergência de uma forma de coletivo.
\end{abstract}

Palavras-chave: pesquisa-intervenção; tecnologias; coletivos; reforma psiquiátrica.

\section{INTERVENTION, RESEARCH AND TECHNOLOGIES: DISPOSITIF FOR COLLECTIVE}

\begin{abstract}
This paper aims to discuss the relation between intervention-research and the use of technological toolworks as dispositif, in the social psychology's field. We take as theoretical intercessors the proposition of Gilbert Simondon, René Lourau and Pierre Lévy. This perspective composition embodied itself in the practice of a technological workshop in a public mental health service network, where the workers builded their website. The technologies work as apparatus of work

^ Psicóloga da Secretaria da Assistência Estudantil da Universidade Federal do Rio Grande do Sul. Secretaria de Assistência Estudantil. Endereço: Av. Paulo da Gama, 110 - Anexo I da Reitoria. Porto Alegre, RS - Brasil.

E-mail: gtanikado@gmail.com

$\star \star$ Pos-doutoramento na Universidade de Wisconsin-Madison/EUA. Professora no Departamento de Psicologia Social e Institucional da Universidade Federal do Rio Grande do Sul. Endereço: Departamento de Psicologia Social e Institucional. Rua Ramiro Barcelos, 2600. Santana - Porto Alegre, RS - Brasil.

E-mail: cleci.maraschin@gmail.com
\end{abstract}


practice's virtualization, provoking his problematization, and building analysts, as the co-habitation of dichotomic discourses about care in mental health, derived from the manicomial model and from the propositions of the psychiatry reform. The workshop worked as a space of another form of conversation between the workers and researchers, provided by the relation mediated by the activity of producing the website. We suggest, therefore, that the operative technique possible conditions for the emergence of a form of collective.

Keywords: intervention-research; technologies; collectives; psychiatry reform.

Este trabalho objetiva discutir uma experiência de pesquisa que consiste em utilizar ferramentas tecnológicas como dispositivo de intervenção, a fim de observar seus efeitos na problematização dos modos de trabalhar de um grupo composto de trabalhadores de um serviço de saúde mental e de pesquisadores universitários. Tomamos como intercessores teóricos as proposições de Gilbert Simondon, René Lourau e Pierre Lévy. Tal composição de perspectivas ganha corpo neste artigo através de uma oficina tecnológica em um serviço da rede pública de atenção à saúde mental, o Centro Integrado de Atenção Psicossocial (CIAPS), na qual os próprios trabalhadores do serviço construíram seu website.

$\mathrm{Na}$ oficina, as tecnologias operam como dispositivos de virtualização das práticas do CIAPS, ou seja, como agentes de problematização. Destaca-se, entre os analisadores produzidos nesse processo, a coabitação de discursos dicotômicos sobre as formas de cuidado em saúde mental, derivados do modelo manicomial e do proposto pela Reforma Psiquiátrica. A oficina possibilitou um espaço no qual referências identitárias fortemente instituídas dentro da lógica psiquiátrica (trabalhadores da saúde mental) e da lógica acadêmica (pesquisadores) puderam tornar-se mais fluidas, a partir da experimentação de outra forma de conversa, proporcionada a partir da relação mediada pela atividade de produzir o website. Apontamos, assim, que a operatividade técnica possibilitou condições para a emergência de outra configuração coletiva.

\section{Encontro entre Oficinando em Rede e CIAPS: esPaÇo de invenção}

Iniciamos este artigo situando o espaço onde se produzem as questões aqui apresentadas: o encontro entre o Centro Integrado de Atenção Psicossocial (CIAPS) e projeto Oficinando em Rede.

O CIAPS é um serviço que presta atendimento em saúde mental a crianças e adolescentes em sofrimento psíquico. É parte da estrutura do Hospital Psiquiátrico São Pedro, ligado à Secretaria de Saúde do estado do Rio Grande do Sul (SES), atuando por meio do Sistema Único de Saúde (SUS). Possui um serviço de internação, com dez leitos para crianças e dez leitos para adolescentes, que atende a algumas regiões do estado; e um ambulatório, destinado a crianças e adolescentes no território de abrangência do serviço, na cidade de Porto Alegre. Assim, é possível constatar que o CIAPS está inserido em duas redes distintas: uma estadual, como serviço de alta complexidade, e outra municipal, como ser- 
viço de média complexidade. Essas duas modalidades de trabalho coexistem em um mesmo espaço físico, localizado em um prédio que margeia o hospital, com acesso a partir de uma movimentada avenida.

Mesmo estando localizado em um hospital psiquiátrico, o CIAPS mantém pontos de abertura às estratégias desinstitucionalizantes advindas da Reforma Psiquiátrica. Nessa modalidade de cuidado aos sujeitos que passam pela experiência da loucura, são consideradas mais dimensões do que apenas o tratamento ao sofrimento. A Reforma Psiquiátrica propõe mudanças nas esferas epistemológicas, técnicas-assistenciais, jurídico-políticas e socioculturais (AMARANTE, 2003). O próprio fato de o CIAPS acolher o projeto Oficinando em Rede revela um dos laços estratégicos das mudanças propostas pela Reforma.

O Oficinando em Rede é um projeto de pesquisa e extensão ligado ao Instituto de Psicologia da Universidade Federal do Rio Grande do Sul. Tem como principal foco de pesquisa e atuação oficinas utilizando ferramentas tecnológicas (fotografia, internet, vídeo) como dispositivos, principalmente no campo da saúde mental (MAURENTE, 2010; DIEHL, 2011; TANIKADO, 2011; VIANNA; MARASCHIN; RICKES, 2011). A parceria do CIAPS foi mantida no período entre 2005 e 2010.

\section{CONHECER E TRANSFORMAR: ALGUNS CAMINHOS DA PESQUISA-INTERVENÇÃo}

A partir de Simondon (2009), compreendemos que o ato de pesquisar se constitui no encontro entre os elementos moventes - pesquisador e campo de pesquisa. Esses elementos se redefinem a partir da própria processualidade da interação. Assim, interessa-nos o que acontece nesse encontro, na conformação e na transformação desses elementos durante o percurso do pesquisar. Ao deixarmos uma posição substancialista, que parte de elementos preexistentes, assumimos que não há uma identidade do ser a respeito de si. O que há é uma forma que está individuada, mas que contém potencialidades e virtualidades que habitam sua configuração atual.

Consideramos que as proposições anteriores se articulam com os pressupostos da Análise Institucional na distinção entre instituído/instituinte. Para essa abordagem, as instituições são normas reatualizadas, formadas pela articulação entre a ação histórica de indivíduos, grupos, coletividades. Essas normas podem aparecer como fixas e eternas, descontextualizadas de sua produção histórica e temporal, formando o instituído. Parafraseando Simondon, as instituições poderiam ser pensadas como formas individuadas. A Análise Institucional busca interrogar essa produção, provocando o questionamento em relação ao que está posto (LOURAU, 2004).

A análise de implicação é ferramenta fundamental nesse processo: opõe-se às pretensões de objetividade, pondo fim à busca de uma neutralidade analítica. A implicação pretende ser uma produção simultânea aos analisadores, baseada na indissociabilidade entre a vida e as instituições. Assim como o campo de intervenção, o pesquisador é também atravessado pelo que o instituiu (LOURAU, 2004). 
Pesquisadores e trabalhadores se instituem na modulação fractal entre macroinstituições e micropolíticas - atualizações que trabalhadores do CIAPS e pesquisadores do projeto Oficinando em Rede fazem em suas práticas nessas instituições. Rocha e Uziel (2008, p. 536) comentam a complexidade da análise de implicação:

[...] considerando como desafio a analítica das implicações coletivas com a produção do sentido, processo que transversaliza metodologia e problema de pesquisa, produção de conhecimento e produção de modos de existência. Uma pesquisa está imersa em um campo de forças, constituindo e ao mesmo sendo efeitos dos saberes/poderes atravessados nos modos de subjetivação.

O pesquisador atua percorrendo a trama do acontecimento, fazendo escolhas, puxando alguns fios que a compõem. Esses fios, numa perspectiva da Análise Institucional, podem ser compreendidos como analisadores e se constituem pelos acontecimentos, fatos, práticas, indivíduos que enunciam em seu funcionamento o instituído, o saber ou não saber de um coletivo em análise sobre si mesmo. $\mathrm{O}$ pesquisador não se posiciona como um intérprete, mas como agente de invenção de novas possibilidades, de rupturas de sentido (AGUIAR; ROCHA, 2007). É através de sua ação que se constitui o campo para a emergência dos analisadores (LOURAU, 2004) e, como afirmam as autoras, se retroage sobre a própria ação do pesquisar.

Mas a ação do pesquisador não é nua, está acoplada, como afirmado, a uma rede de discursos instituídos e a tecnologias. Ao nos alinharmos com a proposta de produção de conhecimento da pesquisa-intervenção, as tecnologias agem como dispositivos ao auxiliar a criar uma trilha a percorrer durante esse processo.

Tomamos a noção de dispositivo desenvolvida por Gilles Deleuze (1990) a partir de Michel Foucault. Deleuze aponta que, entre as dimensões de um dispositivo, estão as curvas de visibilidade e as curvas de enunciação, definindo-o como máquinas de fazer ver e de fazer falar. Nesse mesmo sentido, Kastrup e Barros (2009) afirmam que o que caracteriza um dispositivo é sua capacidade de irrupção do que se encontra bloqueado para a criação. O dispositivo tensiona, movimenta, desloca. É feito de conexões e produz outras. Podemos dizer, com Lévy (1996), que ele opera a virtualização, produzindo brechas de vir-a-ser do pré-indivividuado que habita todo elemento que tomamos como individuado/instituído.

\section{TeCnOlOgias E MÁQuinas COMO DISPOSITIVOS DE INTERVENÇ̃̃o}

A utilização de tecnologias digitais como forma de intervenção em saúde mental surge na busca por estratégias de ação diferenciadas pautadas nas políticas de Reforma Psiquiátrica e de implementação dos Centros de Atenção Psicossocial (CAPS). As características próprias dos meios digitais podem atuar nos projetos terapêuticos abrangendo outras dimensões relacionadas ao cuidado da loucura. Possibilita a ampliação desse cuidado, não focando sua ação somente nas patologias (MARASCHIN; FRANCISCO; DIEHL, 2011). A possibilidade 
de criação de caminhos a serem percorridos é ampliada, já que o espaço virtual possui direcionamentos, mas também infinitas possibilidades de ligar pontos diferentes a cada navegação, formando trajetórias singulares e menos marcadas pelas estigmatizações que guiam o percurso dos sujeitos que trabalham com a experiência da loucura. No ciberespaço, trabalhadores, usuários e pesquisadores estão menos diferenciados, já que no uso das ferramentas técnicas todos têm familiaridades muito próximas - todos utilizam-nas como usuários da tecnologia.

Os efeitos das novas tecnologias têm sido alvo de debates em âmbitos diversos. Implicações negativas para certo entendimento da condição humana são referidas, como seus efeitos no mundo do trabalho. Um conjunto de argumentos pessimistas enfatiza a substituição do homem pela máquina, aumentando o desemprego e intensificando os afazeres dos que conseguem manter seus postos de trabalho. Vale ainda mencionar uma transformação no conteúdo do trabalho e as implicações psicológicas e emocionais para o trabalhador, como a perda do sentido do trabalho, haja vista a falta de identificação com este, ou seja, tem-se uma submissão ao ritmo da máquina e do controle sobre suas práticas (HOLZMANN, 2002). Em outro nível de análise, cabe destacar a possibilidade do empobrecimento da linguagem verbal como mediador na comunicação pelo uso excessivo das tecnologias digitais (JIMENEZ, 2005).

$\mathrm{O}$ rechaço à tecnologia não é um acontecimento particularmente contemporâneo. A tecnofobia, ou seja, uma aversão às tecnologias já é descrita e analisada por Gilbert Simondon ${ }^{1}$ (2008). O autor contrapõe o estranhamento do humano à técnica, afirmando que a gênese e desenvolvimento técnico são paralelos ao desenvolvimento da cultura. Assim, não haveria uma separação entre a produção cultural - com atividades humanas, vivas, dotadas de sentido, condicionadas pelo pensamento social e pelos rituais coletivos - e a técnica, composta por objetos que contêm operatividades humanas e são produtos culturais, carregando consigo potencialidades e qualidades da cultura.

Essa perspectiva é primordial para pensarmos o uso das tecnologias como potencializadoras de outras relações. As tecnologias complexificam as interações sociais e provocam o questionamento sobre as novas formas de vida em comum que podem se desenvolver nesse acoplamento (TIRADO, 2006). Como exemplo, é possível citar as mudanças nos modos de escrever a partir do suporte informático, que pode reunir pessoas com condições perceptivas distintas (cegos, surdos e ouvintes) para uma produção coletiva (DEMOLY, 2011); a expansão e organização de redes de colaboração solidária (EDELWEIN; MARASCHIN, 2003); e atuação como ferramenta na educação que favorece a interação entre alunos e professores (REAL; MARASCHIN; AXT, 2007).

Nas intervenções em saúde mental, as tecnologias podem se constituir em ferramentas potentes. Inseridas em oficinas, criam outras experiências de vida para pessoas em sofrimento psíquico, devido a sua capacidade de convergência de mídias e de atividades em conjunto (FRANCISCO; AXT; MARASCHIN, 2007). As tecnologias podem, ainda, atuar como suporte para sujeitos que não encontravam formas de expressão, ao possibilitar a utilização de recursos diferenciados de con- 
vocação à interação (MARASCHIN et al, 2007) e de produção de narrativas de si (VIANNA; MARASCHIN; RICKES, 2011). A tecnologia, ainda, traz outra velocidade para dentro dos estabelecimentos de saúde mental, provocando questões aos modos como estão organizadas relações de trabalho e de interação.

É importante atentar que não há a pretensão de instrumentalizar os participantes das oficinas para o uso da tecnologia, mas ofertá-la como potencialidade de invenção de si e de seu trabalho.

\section{A OfICINA de CONSTRUÇão do WEBSITE}

A proposta de construção de um website do CIAPS por seus trabalhadores pretendeu atuar como disparadora de uma aproximação maior da equipe do serviço às ferramentas tecnológicas. Apostamos, ainda, que o exercício que propomos se constituiu como um dispositivo de virtualização do próprio CIAPS.

Utilizamos a virtualização e a atualização como operadores conceituais de acordo com as definições propostas por Pierre Lévy (1996) e que encontram consonância com a noção de individuado/individuação (SIMONDON, 2009) e instituído/ institutuinte (LOURAU, 2004) apresentadas anteriormente. O virtual, diferenciando-se do possível, não contém possibilidades a serem selecionadas, mas configurase como campo problemático, nó de tendências ou de forças que acompanha uma situação, um objeto ou uma entidade qualquer. O complexo problemático do virtual está presente nas entidades e se constitui como uma de suas maiores dimensões. $\mathrm{O}$ encaminhamento a um processo de resolução - a atualização - se dá a partir das coerções que são próprias de cada entidade, provocando a invenção e a coprodução de soluções a partir dos encontros com a diversidade de circunstâncias.

A atualização, assim, é o processo que desencadeia a solução do problema posto pela virtualização. Solução esta que não estava contida previamente no enunciado, mas que surge da criação, invenção de uma forma a partir de uma configuração dinâmica de forças e finalidades. É a produção de qualidades novas e transformação de ideias, não se assemelhando ao virtual, mas respondendo-lhe.

A passagem de um modo de ser a outro é um processo dinâmico. Assim como o virtual passa a atual, esse volta a se virtualizar. A entidade carrega e produz suas virtualidades, sendo que um acontecimento pode reorganizar uma problemática anterior - atualizar-se, portanto - e ficar suscetível à constituição de um novo problema e de uma nova virtualização. Esse, então, seria o movimento inverso da atualização, uma passagem do atual ao virtual e elevação à potência da entidade considerada. A atualização, assim, vai do problema à solução. Ou seja, virtualização da solução dada a outro problema.

Foi com o propósito de virtualizar o CIAPS, ou seja, proporcionar um espaço de problematização dos modos de trabalhar, organizar e pensar o serviço, que começamos a negociação e planejamento em conjunto com os trabalhadores. 
Iniciamos participando das reuniões semanais da equipe técnica do serviço, formada por assistentes sociais, enfermeiro, terapeutas ocupacionais, médicos clínicos, médico neurologista, médico foniatra, médicos psiquiatras, psicólogos, psicopedagogos e educador físico. Nas reuniões, apresentamos o convite a todos os trabalhadores e combinamos a configuração da oficina: oito encontros de duas horas para a produção da página por um grupo formado por membros da equipe, já que não seria possível a participação de todos os trabalhadores do serviço (17, no total), visto que o Laboratório de Informática localizado no CIAPS possui cinco computadores. Após a produção, haveria uma apresentação à equipe toda. Assim, começamos a oficina com nove trabalhadores e três oficineiros do projeto Oficinando em Rede.

Um dos objetivos desses encontros foi o de proporcionar uma familiarização dos trabalhadores com as ferramentas de produção de documentos hipertextuais. Para isso, foi utilizado um editor de linguagem HTML, ${ }^{2}$ o Kompozer. ${ }^{3}$ Os oficineiros do grupo de pesquisa realizaram um treinamento anterior para trabalhar com a ferramenta.

Buscamos em Simondon (2009) a afirmação de que a operação técnica é resultado de uma operação humana, contrapondo a radical separação entre ações de cunho técnico das ações determinadas como humanas ou sociais. Segundo o autor, para a construção de um objeto técnico que funcione o homem precisa representar o funcionamento que coincide com a operação técnica e que a completa. Ou seja, a criação de um objeto técnico é eminentemente uma atividade humana, visto que é um ser humano que deposita uma operatividade naquele ente. A máquina não possui a capacidade de inventar operações, apenas de seguir e combinar determinações nela depositadas.

Pela atividade técnica, o homem cria operações e estas são destacadas do indivíduo que as produz e as pensa. Segundo Simondon (2009), a máquina possui um tipo de impersonalidade que faz com que ela possa se tornar instrumento para um outro homem; a realidade humana que se cristaliza nela é alienável, precisamente porque é destacável. Ou seja, a máquina carrega em si algo de humano e que outro humano pode, dessa forma, reconhecer. Para que um objeto técnico seja reconhecido como técnico e não apenas como útil, isto é, para que ele seja julgado como resultado de invenção, portador de informações e não como utensílio, é necessário que o sujeito que se depara com o objeto técnico se reconheça como portador de formas técnicas.

O reconhecimento de operatividades técnicas inseridas por humanos no objeto e das mesmas operatividades no usuário institui uma relação não somente entre o objeto e seu operador, mas uma realidade interindividual coletiva, ou seja, entre indivíduos que em tempos diferentes se relacionam com o objeto técnico (seja criando suas operatividades, seja operando-o). Essa relação é denominada pelo autor como transindividual.

Também Lévy (1999) afirma o caráter humano do desenvolvimento das tencologias: as técnicas não são exteriores à humanidade. $\mathrm{O}$ uso de ferramentas seria, juntamente com a linguagem e as instituições complexas, uma das caracte- 
rísticas constituintes do humano. A partir desse uso é que são imaginadas, fabricadas e reinterpretadas as ferramentas e se dá o desenvolvimento técnico (LÉVY, 1999). Logo, não há uma separação radical entre técnica e humanidade.

Baseados nesses pressupostos, iniciamos as oficinas. Os trabalhadores formaram pequenos grupos ou duplas de trabalho e, num primeiro momento, construíram sites sobre temas diversos - a cidade, música, viagens, jovens e aprendizagem. Foi um momento bastante introdutório à utilização das ferramentas, já que os participantes tinham diferentes níveis de conhecimento das tecnologias digitais: alguns pareciam muito à vontade, outros tinham pouca experiência com os mesmos. Foram produzidos websites coloridos, cheios de imagens e referências a momentos de lazer e descontração.

Em seguida, iniciou-se a produção do site do CIAPS, com um planejamento conjunto do que o constituiria. Esse exercício foi realizado utilizando papel e caneta, designando uma folha para cada uma das páginas do site. A figura a seguir reproduz a ideia dessa primeira fase:

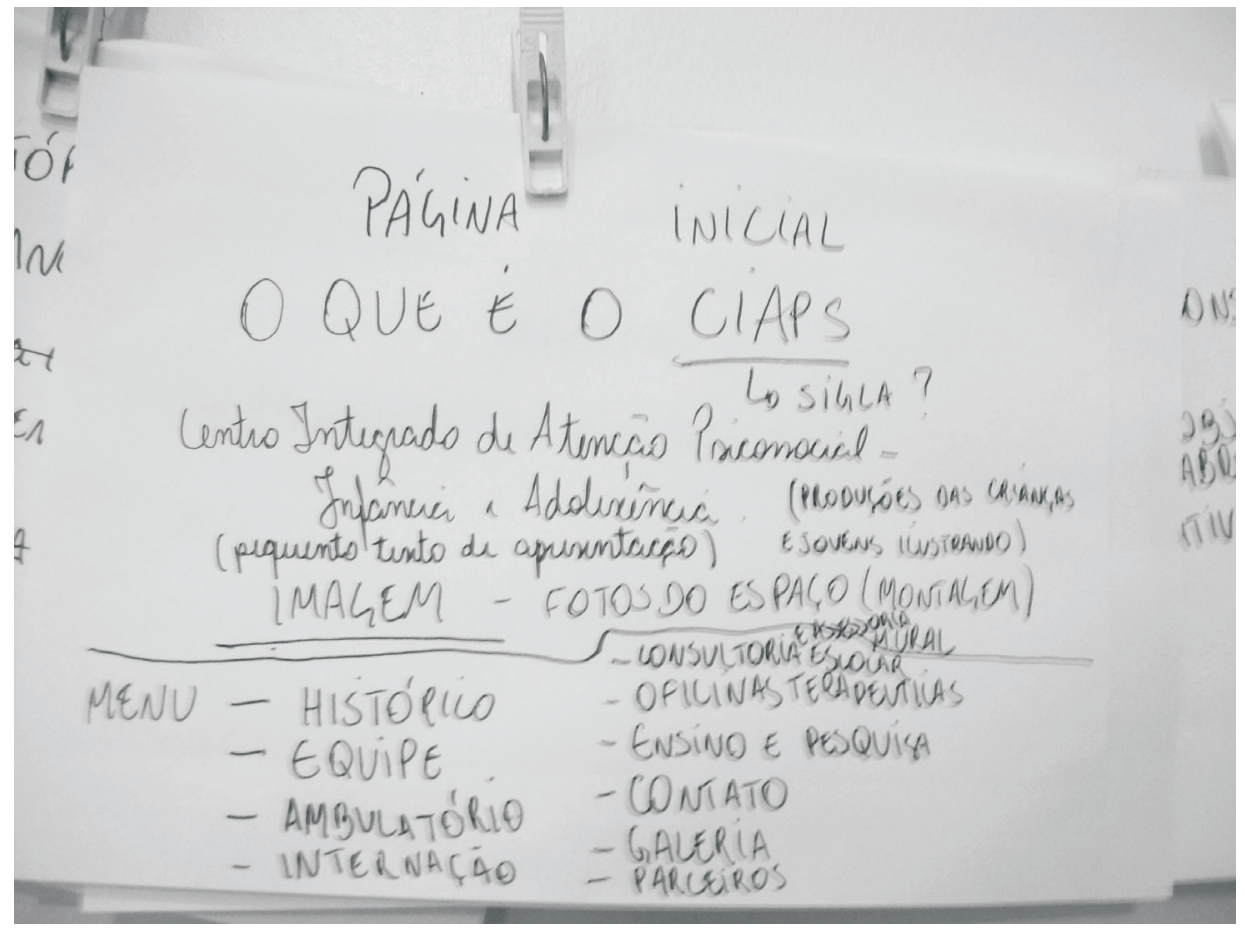

Figura 1: Planejamento da página inicial

Nesse momento, o CIAPS se desenha. É um momento dinâmico, no qual todos falam ao mesmo tempo, sugerem seções, pensam em conteúdos. São definidas, além da página inicial, onze páginas, que falam da história do serviço, apresentam as atividades, a organização do trabalho. Um momento que ilustra 
a intensidade da produção foi a definição do local que cada atividade do serviço ocuparia no site. Uma das atividades realizadas no CIAPS é a Assessoria e Consultoria Escolar, que atende a escolas e trabalha o relacionamento entre seus diversos agentes - alunos, professores, direção - por meio de acompanhamentos na forma de grupos com os professores. No momento de descrever a Assessoria no site, parte da equipe questionava aos trabalhadores envolvidos nesta atividade qual seria seu lugar: enquadraria-se como ambulatório? Eles mantiveram a posição de que era uma assessoria, e não um trabalho ambulatorial, descrevendo seus percursos pelas escolas e não o atendimento de usuários já identificados no espaço físico do CIAPS. Seguiu-se novamente a afirmação de seu lugar no ambulatório, visto que no CIAPS “ou se é do ambulatório, ou se é da internação" (sic). Outros integrantes da equipe começaram a se manifestar pela manutenção de um outro espaço, garantindo, então, um hyperlink próprio para a Assessoria e Consultoria Escolar, como é possível ver na imagem da página inicial do site (Figura 2).

O impasse sobre a localização da Assessoria Escolar visibiliza a dicotomia sob a qual está organizada a atenção à saúde mental: é preciso nomear-se como uma ou outra modalidade, não haveria caminhos alternativos ao ambulatório e internação. A afirmação de que o que se faz no CIAPS deve enquadrar-se a duas modalidades circunscritas também toca a equipe de pesquisa e põe em questão o trabalho das oficinas realizadas com as crianças e jovens no local.

A partir desse exercício inicial de planejamento, os trabalhadores passaram a produzir as páginas no editor HTML, em duplas ou trios. Em seguida, a página foi apresentada a toda a equipe, que demonstrou grande interesse na descrição das atividades e fez diversos questionamentos e sugestões. Dentre eles, uma discussão sobre a nomenclatura utilizada na descrição das atividades: foram localizadas como "oficinas" as atividades realizadas em grupo no CIAPS. Alguns trabalhadores, porém, disseram estar incomodados com tal título e pouco familiarizados com sua realização. Sugeriram a utilização de termos como grupos terapêuticos ou grupos operativos. A equipe dirigiu-se aos oficineiros em vários momentos da discussão, procurando uma resposta para a questão, sobre "o que mesmo eles faziam" ou "qual a diferença entre grupos e oficinas". Nesses instantes, foi importante a retomada da relação do grupo de pesquisa com o CIAPS: a pesquisa não objetivava trazer respostas ou transmitir conhecimento de forma vertical. Ao contrário, participamos como catalisadores de uma construção autoral dos próprios profissionais sobre seus fazeres e conhecimentos. O encaminhamento para essa questão, então, foi utilizar os dois termos: oficinas e grupos terapêuticos.

A partir de discussões como a desse ponto, envolvendo o conjunto dos trabalhadores do serviço, o grupo que participou da oficina realizou as alterações sugeridas e finalizou uma versão inicial do website. 


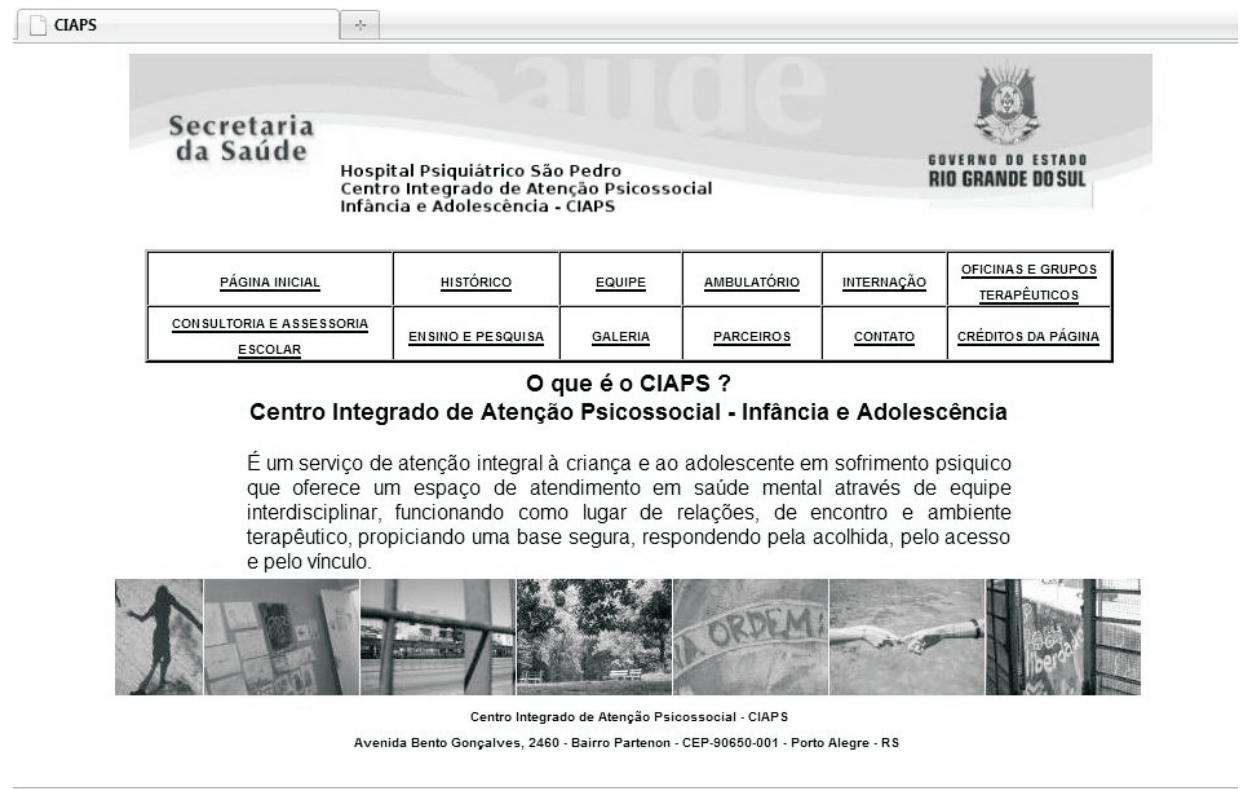

Concluído

Figura 2: Página inicial do Site do CIAPS

O Hospital Psiquiátrico São Pedro (HPSP) possui uma página institucional hospedada dentro do website da Secretaria Estadual de Saúde do Rio Grande do Sul (SES). A coordenação do CIAPS, então, iniciou contatos com a SES a fim de utilizar esse espaço. Participamos de uma reunião com o responsável pelo site do HPSP, que informou que a página do CIAPS não poderia ser publicada tal como havia sido produzida, já que o site da SES possuía uma pré-configuração de alguns elementos. Acertou-se, assim, que a página seria publicada seguindo o formato padrão, mas com conteúdo produzido pela equipe.

O site do CIAPS, então, ficou localizado como uma das unidades de internação do HPSP, mesmo tendo atividades em outras modalidades de atendimento - como o ambulatório e a assessoria. Atualmente, o CIAPS segue buscando outras formas de publicação da página em sua forma produzida pelos trabalhadores, já modificada a partir dos acontecimentos após a publicização do website junto ao Hospital e à Secretaria, e o Oficinando segue atuando na assessoria desse processo.

"Virtualizando o CIAPS, virtualizando o Oficinando: inventando relações"

A utilização de ferramentas tecnológicas, por meio das oficinas de construção do website, teve como objetivo de partida servir como dispositivo para a emergência de um campo problemático no CIAPS, virtualizando sua organização e suas relações internas e externas. De início, percebemos que o encontro possui uma dupla direção, motivando ampliar nosso olhar nesse trabalho e incluindo, também, os pesquisadores. 
O encontro com a tecnologia informática pode, à primeira vista, causar desconforto para aqueles que ainda não vivem cotidianamente conectados a computadores e redes de internet. $\mathrm{O}$ salto ocorrido na difusão das tecnologias de informação e comunicação criou uma diversidade nos modos de relação com essas máquinas e redes e forma diversas ecologias cognitivas (LÉVY, 1997): há aqueles que têm a tecnologia informática como base de suas ecologias cognitivas; há os que a incorporaram em seu funcionamento; há aqueles que se aproximam e fazem dela um utilitário, e ainda outras tantas formas de relação.

Assim, anteriormente a uma utilização da tecnologia como dispositivo de intervenção em nossos fazeres - trabalhadores do CIAPS e pesquisadores do Oficinando -, temos um encontro com esse aparato em nossas cognições. As formas de relação que produzimos singularmente com a tecnologia são confrontadas a partir da proposta de trabalho do Oficinando. Um confronto que se desdobra ainda por outra seara muito delicada no campo em que atuamos: as práticas em saúde mental, ligadas a profissões do cuidado e assistência, que têm seus desenvolvimentos alicerçados sobre uma base de formação humana, em sua acepção tradicional de separação da técnica.

Assim, enfrentamos um duplo confronto: como nos constituímos em relação a tecnologia informática e o que isso tem a ver com o trabalho que desenvolvemos em saúde mental? O que foi possível demarcar é que o potencial de desterritorialização da tecnologia provoca as relações. Coloca em questão marcas identitárias assumidas em ambientes tão fortemente instituídos: o hospital psiquiátrico e a universidade.

Assim, como pesquisadores, necessitamos retornar "aos bancos escolares" e passar por uma capacitação para aprendermos a construir websites. Admitimos a parcialidade de nosso conhecimento ao nos depararmos com a dependência de um especialista em tecnologias. Temos ainda que explicar a colegas do mundo psi que nossas intervenções possuem um caráter clínico.

Os trabalhadores do CIAPS lidam com jovens e crianças que, em geral, podem ter mais contato com a tecnologia do que eles próprios. Operar o saber que mantém a relação entre "técnicos" e "pacientes" acaba se tornando um desafio. O que pode emergir em uma relação na qual o sujeito que está ali porque é "louco" pode saber mais sobre aquela operação do que o trabalhador?

A operatividade técnica, tal como definida por Simondon (2008), é resultado de uma operatividade humana. $\mathrm{O}$ autor afirma que a operação humana que compõe a máquina pode ser destacada por outros entes que a utilizem pelo reconhecimento de uma operação que ele também possui. Ou seja, é preciso visualizar na máquina algo de comum a si, de análogo. Assim, ela pode realizar seu potencial transindividual.

Na oficina de construção do website do CIAPS, pudemos experienciar essa ligação pela tecnologia. Trabalhadores do serviço foram capazes de circular por espaços comuns com seus colegas, travando conversas sobre temas que não eram somente os ligados ao trabalho. Uma sensibilização para uma forma de conversa 
nova, produzida pela hipertextualidade: o website é um ponto que pode se ligar a tantos outros na internet. O que pode se falar sobre seu trabalho? Quem irá ler o que eles escrevem? Um possível usuário, um profissional que busca um espaço de encaminhamento, um estudante em busca de campo de estágio? Como cada um desses entes pode ler o que está na página?

Operar as máquinas coloca os trabalhadores em outro regime de produção. As distinções entre saberes ficam diluídas durante o processo: todos estão aprendendo, todos estão falando, todos estão produzindo. A tecnologia atuou nessa experiência como a "bola do jogo", objeto-ligação que faz disparar a conversa e media a relação. Esse objeto seria o responsável por levar o todo a cada sujeito e cada sujeito ao todo (LÉVY, 1996). A discussão é produzida a partir do suporte tecnológico que confere forma a essa produção. Surgiram, assim, questões sobre temas presentes naquele campo, mas que ficam submersos em meio a um cotidiano de práticas já instituídas.

Além dos desafios diante das problematizações mencionadas, a conexão em rede engata os participantes no estabelecimento de conversas com o mundo digital. Poder operar com modos de linguagem que são comuns a uma comunidade de internautas certamente fornece ferramentas de pertencimento, de exercício ampliado de cidadania, capacitando-nos a uma distinção entre diferentes encontros nesses outros mundos.

Concordamos com Escóssia (2009) quando afirma, baseada em Simondon, que o coletivo não é um plano transcendente, mas imanente. Ou seja, não se encontra em outro espaço, como nas normativas ou prescrições de um trabalho conjunto, mas sim no plano concreto de ações e experiências.

Como afirma Simondon (2009), há uma nova individuação quando acontece um movimento coletivo. Não é criado somente um novo território, mas também novos movimentos naqueles que se propuseram ao encontro. Dessa forma, nesta experiência, CIAPS e Oficinando em Rede se reinventam.

A utilização de tecnologias como dispositivo de intervenção psi se apresenta como um desafio. Uma escolha que requer que os pesquisadores-oficineiros tenham contato com saberes muito diversos daqueles de suas formações iniciais. Uma estratégia que não produz modificações somente no campo em que acontece a intervenção, nesse caso, no CIAPS, mas também no próprio projeto Oficinando em Rede.

Destacamos, assim, a potencialidade da tecnologia como ferramenta de intervenção, produzindo efeitos que podem se atualizar a cada novo encontro.

\section{Notas}

${ }^{1}$ Os trabalhos de Simondon foram originalmente publicados nas décadas de 1950 e 1960.

${ }^{2}$ Hypertext Markup Language (linguagem de marcação hipertextual). Coleção de comandos de formatação que criam comandos hipertextuais, ou seja, páginas da web (COSTA, 1999).

${ }^{3}$ Programa utilizado para produção de sites, de livre distribuição. Considerado de fácil operação, não necessita de conhecimentos sobre programação de sistemas para ser utilizado, já que possui uma interface muito próxima a um editor de textos. 


\section{REFERÊNCIAS:}

AGUIAR, K. F.; ROCHA, M. L. Micropolítica e o exercício da pesquisaintervenção: referenciais e dispositivos em análise. Psicologia: ciência e profissão, Brasília, v. 27, n. 4, p. 648-663, dez. 2007.

AMARANTE, P. (Coord.). A (clínica) e a reforma psiquiátrica. In: Archivos de saúde mental e atenção psicossocial. Rio de Janeiro: NAU, 2003. p. 45-65.

COSTA. C. I. Glossário. In: LÉVY, P. Cibercultura. São Paulo: Editora 34, 1999. p. 251-260.

DELEUZE, G. Que és un dispositivo?. Michel Foucault, filósofo. Tradução de Wanderson Flor do nasciemento. Barcelona: Gedisa, 1990. p. 155-161. Disponível em: <http://escolanomade.org/pensadores-textos-e-videos/deleuze-gilles/o-quee-um-dispositivo>. Acesso em: 9 abr. 2010.

DEMOLY, K. Tecnologias em atos de escrita: quando o oficinar permite habitar outros mundos. In: MARASCHIN, C.; FRANCISCO, D. J.; DIEHL, R. (Org.). Oficinando em Rede: oficinas, tecnologias e saúde mental. Porto Alegre: UFRGS, 2011. p. 205-226.

DIEHL, R. Metodologia para superfícies e operacionalidades. In: MARASCHIN, C.; FRANCISCO, D. J.; DIEHL, R. (Org.). Oficinando em Rede: oficinas, tecnologias e saúde mental. Porto Alegre: UFRGS, 2011. p. 57-70.

EIDELWEIN, K.; MARASCHIN, C. O operar de um coletivo na web. Psicologia: Ciência e Profissão, Brasília, v. 23, n. 3, p. 48-55, 2003. Disponível em: $\quad<$ http://pepsic.bvs-psi.org.br/scielo.php?script=sci_arttext\&pid=S141498932003000400008\&lng=es\&nrm=iso >. Acesso em: 01 abr. 2008.

ESCÓSSIA, L. O coletivo como plano de criação na Saúde Pública. Interface, Botucatu, v. 13, p. 689-694, 2009. Disponível em <http://www.scielo.br/scielo. php? script $=$ sci_arttext\&pid $=$ S1414-32832009000500019\&lng $=$ en\&nrm $=$ iso $>$ Acesso em 5 abr. 2010.

FRANCISCO, D.; AXT, M.; MARASCHIN, C. Informática e saúde mental: caminhos de uma oficina. RENOTE: Revista Novas Tecnologias na Educação, Porto Alegre, v. 5, n. 1, p. 1-16. 2007. Disponível em: <http://www.cinted.ufrgs. br/ciclo9/artigos/10cDeise.pdf.>. Acesso em: 01 abr 2008.

HOLZMANN, L. Novas Tecnologias. In: CATTANI, A. D. Dicionário Crítico sobre Trabalho e Tecnologia. Porto Alegre: UFRGS, 2002. p. 224-228. 
JIMÉNEZ, R. V. Educação, poder e mercado: desconstrução crítica dos efeitos disciplinantes das TIC na nova Escola do Espetáculo. Interface - Comunicação, Saúde, Educação, São Paulo, v. 9, n. 18, p. 475-488, set./dez. 2005.

KASTRUP, V.; BARROS, R. B. Movimentos funções do dispositivo na prática da cartografia. In: PASSOS, E.; KASTRUP, V.; ESCÓSSIA, L. Pistas do método cartográfico: pesquisa-intervenção e produção de subjetividade. Porto Alegre: Sulina, 2009. p. 76-91.

LÉVY, P. As tecnologias da inteligência: o futuro do pensamento na era da informática. Rio de Janeiro: Ed. 34, 1997.

LÉVY, P. Cibercultura. São Paulo: Editora 34, 1999.

LÉVY, P. O que é o virtual?. São Paulo: Editora 34, 1996.

LOURAU, R. Objeto e método da análise institucional. In: ALTOÉ, S. (Org.). René Lourau: analista institucional em tempo integral. São Paulo: Hucitec, 2004. p. 66-86.

MAURENTE, V. Imagens do hospício vazio: fotografia, pesquisa e intervenção. 2010. Tese (Doutorado)-Programa de Pós-graduação em Informática na Educação, Universidade Federal do Rio Grande do Sul, Porto Alegre, 2010.

MARASCHIN, C.; FRANCISCO, D. J.; DIEHL, R. (Org.). Oficinando em Rede: oficinas, tecnologias e saúde mental. Porto Alegre: UFRGS, 2011.

MARASCHIN, C. et al. Projeto oficinando em rede. Porto Alegre: Instituto de Psicologia/Faculdade de Educação, UFRGS, 2007. Relatório de Pesquisa. Mimeografado.

REAL, L. C.; MARASCHIN, C.; AXT, M. Projetos de aprendizagem e tecnologias digitais: uma experiência promovendo transformações na convivência na escola. RENOTE: Revista Novas Tecnologias na Educação, Porto Alegre, v. 5, n. 1, p. 1-11, 2007.

ROCHA, M.; UZIEL, A. P. Pesquisa-intervenção e novas análises no encontro da psicologia com as instituições de formação. In: CASTRO, L. R.; BESSET, V. L. (Org.). Pesquisa-intervenção na infância e juventude. Rio de Janeiro: NAU/ Faperj, 2008. p. 532-556.

SIMONDON, G. El modo de existencia de los objectos ténicos. Buenos Aires: Prometeo-Paidós, 2008.

SIMONDON, G. La individuacion. Buenos Aires: Cactus-La Cebra, 2009. 
TANIKADO, G. V. F. Os encontros entre Oficinando e CIAPS: virtualizando instituições. In: MARASCHIN, C.; FRANCISCO, D. J.; DIEHL, R. (Org.). Oficinando em Rede: oficinas, tecnologias e saúde mental. Porto Alegre: UFRGS, 2011. p. 149-162.

TIRADO, F. S. Lo social y lo virtual. In: TIRADO, F. S.; DOMÈNECH, M. A. Lo social y lo virtual: nuevas formas de control y transformación social. Barcelona: UOC, 2006. p. 5-27. Colección Nuevas Tecnologías y Sociedad.

VIANNA, T. ; MARASCHIN, C; RICKES, S. O encontro com as tecnologias na atenção em saúde mental infantojuvenil. In: MARASCHIN, C.; FRANCISCO, D. J.; DIEHL, R. (Org.). Oficinando em Rede: oficinas, tecnologias e saúde mental. Porto Alegre: UFRGS, 2011. p. 79-98.

Recebido em: 09 de agosto de 2010 Aceito em: 14 de março de 2012 
